\title{
PRODUÇÃO DE BIOETANOL DE SEGUNDA GERAÇÃO A PARTIR DO HIDROLISADO DO ALBEDO DA LARANJA COMO FONTE DE BIOMASSA LIGNOCELULÓSICA
}

\author{
D. P. C. ANTUNES ${ }^{1}$, V. L. VIANA ${ }^{1}$, M. C. S. SANTOS ${ }^{1}$, E. L. S. SOARES ${ }^{1}$, \\ K.L. BARBOSA ${ }^{1}$, K. L. MOURA R. C. VIEIRA ${ }^{1}$, R. M. R. G. ALMEIDA ${ }^{1}$ \\ ${ }^{1}$ Universidade Federal de Alagoas, Centro de Tecnologia, Departamento de Engenharia \\ Química
}

E-mail para contato: renatarosas_ufal@hotmail.com

\begin{abstract}
RESUMO - A laranjeira é uma árvore frutífera do gênero Citrus, pertencente à família das rustáceas. Atualmente a laranjeira faz parte das culturas mais conhecidas e estudadas no mundo. Os resíduos provenientes da extração do suco da laranja são constantemente descartados em grandes proporções no meio ambiente. O Brasil possui papel de destaque como maior produtor mundial de laranjas, porém, pouco se tem feito sobre o aproveitamento de subprodutos cítricos com as cascas das laranjas. Pensando nisso, o objetivo da pesquisa foi estudar o pré-tratamento do albedo da laranja com diferentes ácidos $\left(\mathrm{H}_{2} \mathrm{SO}_{4}\right.$, $\mathrm{HCl}, \mathrm{HNO}_{3}$ e $\left.\mathrm{H}_{3} \mathrm{PO}_{4}\right)$ 0,5\% e $1 \%$, em tempo de $15 \mathrm{~min}$, baseando-se no rendimento mássico, Brix, açúcares redutores totais (ART) e açúcares redutores (AR). Após secar e triturar o albedo da laranja, este foi pré-tratado na proporção de sólido-líquido de 1:20, no reator do tipo auto-clave, a uma temperatura de $120{ }^{\circ} \mathrm{C}$, e $1 \mathrm{~atm}$ de pressão. Os pré-tratamentos realizados obtiveram valores significativos de AR, ART e ${ }^{\circ}$ Brix, sendo o maior valor encontrado com o prétratamento com ácido sulfúrico 0.5\% (29,27 g/L de AR, 49,92 g/L de ART, $6,16^{\circ}$ Brix e rendimento de $49,66 \%$ ).
\end{abstract}

\section{INTRODUÇÃO}

Atualmente a preocupação com o esgotamento dos combustíveis fósseis aliada à preservação e proteção do meio ambiente, tem despertado a necessidade de investidas em novas fontes de energia para síntese de combustíveis e geração de energia, sem que comprometam o meio ambiente. Além disso, busca-se nos biocombustíveis a característica de sustentar o atual consumo e consequentemente o crescimento econômico. Nessa perspectiva, os resíduos de biomassa agrícola vêm apresentando um papel de destaque no Brasil na geração de bioenergia associado às tecnologias de energia avançadas no país (Ferreira, 2012).

É sabido que a biomassa produzida pelos organismos autótrofos por meio do processo de fotossíntese é uma das formas mais primitivas de energia. Entretanto, a energia da biomassa atualmente representa uma possibilidade de obtenção e uso mais eficiente na forma de etanol do que na queima direta. O etanol pode ser de primeira geração, cujas 
matérias-primas são amido e açúcar, que já estão no mercado em quantidades consideráveis e com tecnologia bem difundida. Ou etanol de segunda geração, que são os biocombustíveis produzidos a partir de materiais lignocelulósicos (International Energy Agency, 2010).

No entanto, a produção do etanol de segunda geração ainda enfrenta grandes desafios no quesito tecnologia e valor econômico para a produção em larga escala, ao passo que os materiais lignocelulósicos apresentam estruturas de proteção à celulose, sendo necessário utilizar o processo de hidrólise ácida ou enzimática (Buckeridge et al., 2010).

A maior discussão a cerca da biomassa lignocelulósica é encontrar o melhor e mais adequado processo de pré-tratamento da biomassa, visto que a dificuldade está em desestruturar a forte ligação existente entre a celulose, hemicelulose e lignina. $\mathrm{O}$ tratamento ideal tende a desorganizar a estrutura da biomassa, proporcionando efetiva ação dos ácidos e enzimas na conversão de carboidratos em açúcares fermentescíveis (Silva, 2010).

As matrizes energéticas de materiais lignocelulósicos são destinadas atualmente para a produção de bioetanol de $2 \mathrm{G}$. Essas matérias-primas representam aproximadamente $50 \%$ da biomassa no mundo, com produção de bioetanol anualmente estimado em cerca de 10 e 50 bilhões de toneladas. É relevante predizer que a lignocelulose tornou-se o componente orgânico mais abundante e renovável da biosfera. Indubitavelmente a biomassa lignocelulósica incorporou um enorme potencial de fontes de energia (Champagne, 2007).

A laranjeira é uma árvore frutífera do gênero Citrus, pertencente à família das rustáceas. Atualmente a laranjeira faz parte das culturas mais conhecidas e estudadas no mundo (Evaristo, 2009). O principal produto comercialmente produzido da laranja é o suco, entretanto outros subprodutos de valor comercial também são gerados no processo de fabricação, tais como: óleos essenciais, d'limoneno, pectina, o farelo de polpa cítrica. Este por sua vez apresenta distintas aplicações de interesse comercial, como a produção de produtos químicos e solventes, aroma e fragrâncias, tintas, cosméticos, geleias, balas, recheios de frutas para panificação e complemento da ração animal (ABECITRUS, 2014).

Segundo Evaristo (2009) os resíduos provenientes da extração do suco da laranja são constantemente descartados no meio ambiente, causando poluição. O Brasil possui papel de destaque como maior produtor mundial de laranjas, porém, pouco se tem feito sobre o aproveitamento de subprodutos cítricos com as cascas das laranjas. O que se sabe é que sua atual utilização se define na produção de ração animal e pectina comercial purificada. Nesse sentindo, devido à escassez de dados que relatem o aproveitamento do albedo da laranja, o presente estudo teve como objetivo avaliar o potencial energético dessa biomassa através do pré-tratamento ácido, e determinação do AR, ART, Brix e Rendimento para a produção de Bioetanol de $2 \mathrm{G}$.

\section{METODOLOGIA}

Todos os ensaios foram realizados no Laboratório de Tecnologia de Bebidas e Alimentos, localizado no Centro de Tecnologia da Universidade Federal de Alagoas. 


\subsection{Pré-tratamento do albedo da laranja}

Esta etapa consistiu em pré-tratar o albedo da casca da laranja com solução de ácido diluído nas concentrações de 0,5 e $1 \%$, os ácidos utilizados no estudo do pré-tratamento foram ácido sulfúrico $\left(\mathrm{H}_{2} \mathrm{SO}_{4}\right)$, ácido fosfórico $\left(\mathrm{H}_{3} \mathrm{PO}_{4}\right)$, ácido clorídrico $(\mathrm{HCl})$ e ácido nítrico $\left(\mathrm{HNO}_{3}\right)$. Cerca de $1 \mathrm{~g}$ de material foi colocado em frasco do tipo Erlenmayer, levando-se em seguida para um reator do tipo auto-clave a 1 atm e $120^{\circ} \mathrm{C}$, e uma proporção de sólido-líquido de 1:20, com tempo de reação de $15 \mathrm{~min}$, todos os experimentos foram realizados em triplicata. Posteriormente, cada amostra foi filtrada, e foram realizadas análises de açúcares redutores (AR), açúcares redutores totais (ART) e Brix, na fração líquida, enquanto que a fração sólida foi secada para analisar o rendimento mássico obtido em cada situação estudada.

\subsection{Determinação de açúcares redutores e açúcares redutores totais pelo método do DNS}

Para determinação do ART é necessária a hidrólise prévia do material como descrito: para este procedimento transfere-se $1,0 \mathrm{~mL}$ de amostra para um tubo e adiciona-se $5 \mathrm{~mL}$ de $\mathrm{H}_{2} \mathrm{SO}_{4} 1,5 \mathrm{M}$, levando-se a banho fervente por 20 min e agitando ocasionalmente para hidrolisar os polissacarídeos e outros açúcares não-redutores (ao menos a cada 5 min). Resfria-se e se adiciona, cuidadosamente, solução de $\mathrm{NaOH} 26 \%$ até neutralizar a amostra, completando-se em seguida o volume com água destilada de acordo com a diluição necessária.

Para determinação de AR e ART segue o procedimento: realiza-se a reação de DNS, onde transfere-se $0,25 \mathrm{~mL}$ da amostra para um tubo de ensaio com tampa e adiciona $0,5 \mathrm{~mL}$ de água destilada. Após Verificar se o banho de água está fervendo, adiciona $0,25 \mathrm{~mL}$ do reagente de DNS e leva a amostra para banho fervente por $5 \mathrm{~min}$, permitindo que ocorra a reação entre a glicose e o DNS. Resfria-se o tubo em banho de gelo, ajuste o volume com água destilada para $5 \mathrm{~mL}$ (ou seja, adicione $4 \mathrm{~mL}$ de água) e lê-se em absorbância a 540nm, tendo como padrão concentrações conhecidas de glicose. A partir da curva padrão de concentrações conhecidas de glicose tem-se a equação da reta que permitirá calcular a concentração de glicose em cada amostra a partir da equação 1, onde a diluição da amostra será dada pela equação 2 .

AR ou ART $(\mathrm{g} / \mathrm{L})$ = fator da curva padrão.Absorbância.diluição

Onde,

Diluição $=$ Volume da amostra $(\mathrm{mL}) /($ Volume Total $)(\mathrm{mL})$

\subsection{Determinação do rendimento do pré-tratamento}

O rendimento é calculado a partir da diferença de massa entre o inicio e o final do pré-tratamento. Pesa-se a massa inicial antes de ser pré-tratada, após o pré-tratamento o 
material é filtrado em papel de filtro previamente pesado e é levado para uma estufa a uma temperatura de aproximadamente $40^{\circ} \mathrm{C}$ até secagem completa do material e do filtro. Em seguida, pesa-se o filtro com o material, onde é feito o calculo do rendimento pela equação 3 , onde a massa final é dada pela equação 4.

$$
\text { Rendimento }=\left[\mathrm{M}_{\text {inicial }}-\mathrm{M}_{\text {final }}\right] / \mathrm{M}_{\text {inicial }}
$$

Onde,

$$
\mathrm{M}_{\text {final }}=\text { Massa do material com o filtro }- \text { Massa do filtro }
$$

\subsection{Determinação do Brix}

O Brix foi determinado por meio do refratômetro digital que forneceu a leitura em grau Brix, servindo como base para comparação com a quantidade de açúcares totais presentes na amostra.

\section{RESULTADOS E DISCUSSÕES}

As Tabelas 1 e 2 mostram os resultados do pré-tratamento do albedo da laranja com diferentes tipos de ácidos nas concentrações de 0,5 e 1\% para cada ácido, respectivamente. Utilizou-se a média e desvio padrão dos níveis de estudo para as variáveis estudadas (AR, ART, Brix e Rendimento).

Tabela 1 - Resultados do pré-tratamento para $0,5 \%$ de ácido.

\begin{tabular}{|l|l|c|c|c|c|}
\hline Biomassa & Ácido & AR (g/L) & ART (g/L) & ${ }^{\circ}$ BRIX & $\begin{array}{c}\text { Rendimento } \\
(\%)\end{array}$ \\
\hline \multirow{4}{*}{ ALBEDO } & $\mathrm{H}_{3} \mathrm{PO}_{4}$ & 25,04 & 42,02 & 4,63 & 29,33 \\
\cline { 2 - 6 } & $\mathrm{HCL}$ & 21,21 & 37,44 & 4,36 & 30,66 \\
\cline { 2 - 6 } & $\mathrm{HNO}_{3}$ & 28,25 & 38,11 & 4,46 & 29,33 \\
\cline { 2 - 6 } & $\mathrm{H}_{2} \mathrm{SO}_{4}$ & 29,27 & 49,91 & 6,16 & 49,66 \\
\cline { 2 - 6 } & Média & 25,94 & 41,62 & 4,90 & 37,74 \\
\cline { 2 - 6 } & Desvio & 3,13 & 4,96 & 0,72 & 9,13 \\
& Padrão & & & & \\
\hline
\end{tabular}

De acordo com as Tabelas 1 dos diferentes ácidos empregados no pré-tratamento o que mais se destacou foi o ácido sulfúrico, gerando maiores valores de AR, ART e Brix, o rendimento mássico também foi alto indicando grande perda de massa durante a reação. Para melhor ilustrar os resultados encontrados para 0,5\% de ácido, pode-se observar Figura 1 onde nota-se que os dados obtidos de AR, ART e Brix para ó ácido sulfúrico estão acima da média dos resultados obtidos, enquanto para os demais ácidos os resultados são bastante semelhantes. 


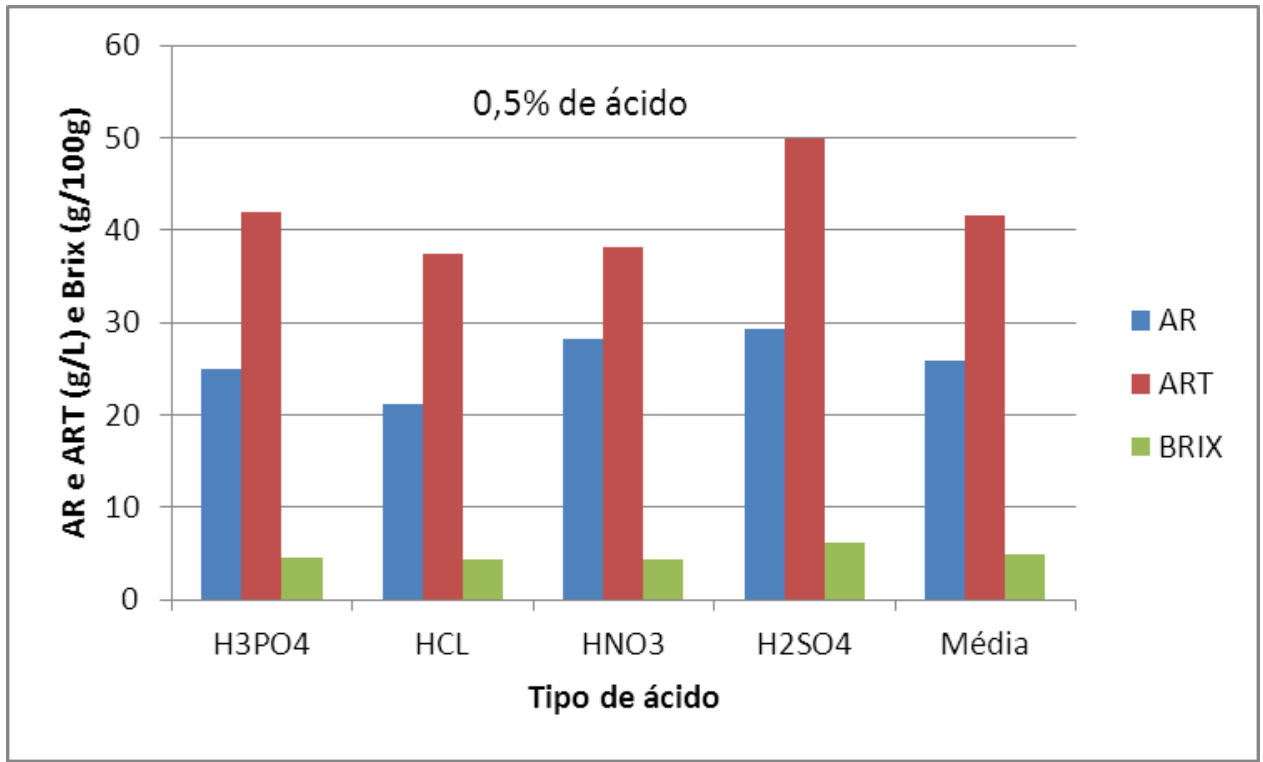

Figura 1 - Açúcares gerados utilizando-se 0,5\% de diferentes tipos de ácidos

Os resultados de pré-tratamento para bagaço de cana de açúcar mostram que ácidos fortes geram mais açúcares redutores do que os ácidos mais fracos, porém ácidos mais fortes, como ácido sulfúrico, geram também mais produtos de degradação (Lorencini, 2013). Outros autores mostram a eficiência do uso de ácido sulfúrico no pré-tratamento de materiais lignocelulósicos. Santos (2014) utilizou ácido sulfúrico para pré-tratar sabugo e palha de milho obtendo 61,5 e $59,4 \%$ de ART, respectivamente usando $2 \%$ de $\mathrm{H}_{2} \mathrm{SO}_{4}$. Montipó (2012) comparou o uso do ácido clorídrico e ácido sulfúrico no pré-tratamento de casca arroz e observou que o $\mathrm{H}_{2} \mathrm{SO}_{4}$ foi melhor obtendo-se $17 \mathrm{~g} / \mathrm{L}$ de glicose com 2,2\% de ácido. Da Silva (2009) também utilizou ácido sulfúrico diluído (1\%) para pré-tratar palha e bagaço de cana de açúcar e pseudo-caule da bananeira para obtenção de etanol obtendo bons resultados para os três materiais.

Tabela 2 - Resultados do pré-tratamento para 1,0\% de ácido.

\begin{tabular}{|l|l|c|c|c|c|}
\hline Biomassa & Ácido & AR (g/L) & ART (g/L) & ${ }^{\circ}$ BRIX & $\begin{array}{c}\text { Rendimento } \\
\mathbf{( \% )}\end{array}$ \\
\hline \multirow{4}{*}{ ALBEDO } & $\mathrm{H}_{3} \mathrm{PO}_{4}$ & 19,09 & 30,43 & 4,90 & 38,33 \\
\cline { 2 - 6 } & $\mathrm{HCL}$ & 21,89 & 34,80 & 4,53 & 30,00 \\
\cline { 2 - 6 } & $\mathrm{HNO}_{3}$ & 28,08 & 35,58 & 4,73 & 27,66 \\
\cline { 2 - 6 } & $\mathrm{H}_{2} \mathrm{SO}_{4}$ & 30,37 & 41,54 & 5,50 & 41,00 \\
\cline { 2 - 6 } & Média & 24,85 & 35,58 & 4,91 & 34,24 \\
\cline { 2 - 6 } & $\begin{array}{l}\text { Desvio } \\
\end{array}$ & 4,54 & 3,95 & 0,36 & 5,55 \\
\hline
\end{tabular}


Assim como ocorreu nos dados mostrados na Tabela 1, pode-se verificar na Tabela 2 que o ácido que gerou maiores valores de açúcares gerados foi o ácido sulfúrico mesmo na concentração de $1 \%$. Porém a quantidade de açúcares liberados na forma de ART foram maiores quando se utilizou apenas $0,5 \%$ de ácido, independente do ácido utilizado indicando que maiores concentrações de ácido podem degradar os açúcares gerados em produtos secundários que podem ter efeito inibidor nas próximas etapas de produção de etanol como na hidrólise e na fermentação. Esses resultados corroboram com os de Santos (2014) que verificou que menores concentrações de ácido sulfúrico foram mais eficientes no pré-tratamento de palha e sabugo de milho. Para melhor ilustrar os resultados encontrados para $1 \%$ de ácido, pode-se observar Figura 2. Semelhante à Figura 1 os resultados para o ácido sulfúrico são maiores que a média dos resultados obtidos, embora sejam menores do que quando usada a concentração de $0,5 \%$ de ácido.

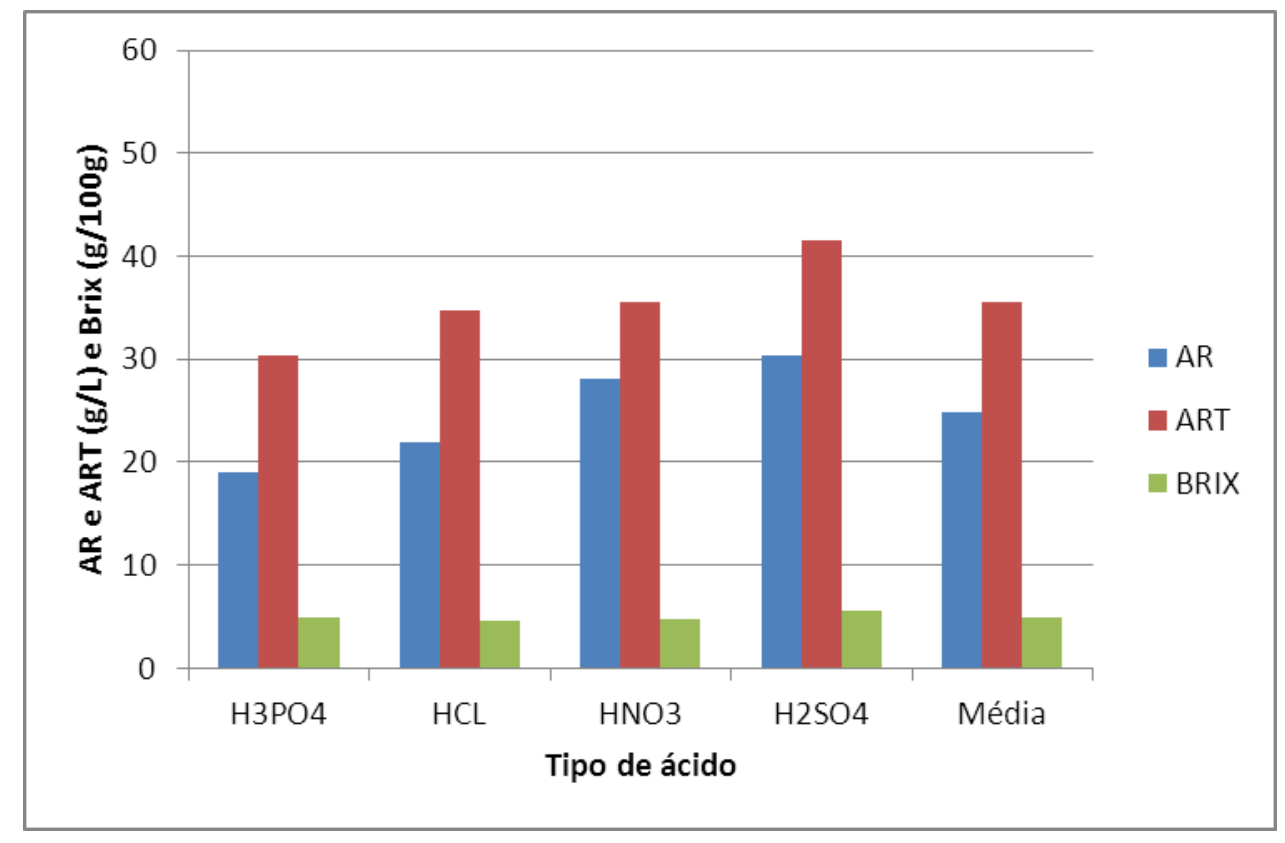

Figura 2 - Açúcares gerados utilizando-se $1 \%$ de diferentes tipos de ácidos.

\section{CONCLUSÕES}

Analisando as tabelas, observa-se que o aumento da concentração de ácido propicia uma diminuição dos valores de AR, ART e BRIX no pré-tratamento. No estudo do prétratamento do albedo da laranja com diferentes tipos de ácido foi possível obter valores significativos de AR, ART, BRIX, indicando o ácido sulfúrico como o mais indicado em comparação aos outros ácidos utilizados. Dessa maneira, os dados apresentados demonstram que o pré-tratamento foi eficaz pois foi capaz de desestruturar a parede vegetal da biomassa, tornando os açúcares fermentescíveis disponíveis no processo de fermentação aos microrganismos para a conversão dos açúcares em etanol de segunda geração. Devido aos possíveis inibidores gerados no pré-tratamento, as melhores condições para esse processo devem ser analisadas após as etapas de hidrólise e fermentação. 


\section{Agradecimentos}

Ao Conselho Nacional de Desenvolvimento Científico e Tecnológico - CNPq Processo No. 552595/2011-0 e Processo No. 420237/2013-5 pelos auxílios financeiros e bolsa PIBIC e ITI.

\section{REFERÊNCIAS}

Associação Brasileira dos Exportadores de Cítricos (ABECITRUS). Disponível em: http://www.abercitrus.com.b r/subprobr.html. Acesso em: 02 de Maio 2014.

BALAT, M. \& BALAT, H. Recent trends in global production and utilization of bioethanol fuel. Appl Energ. 86, 2273-2282. 2009.

BANCO NACIONAL DO DESENVOLVIMENTO (BNDES); CENTRO DE GESTÃO E ESTUDOS ESTRATÉGICOS (CGEE). Bioetanol de cana-de-açúcar: energia para o desenvolvimento sustentável. BNDES: Rio de Janeiro, 2008.

BUCKERIDGE, M. S. et al. As rotas para o etanol celulósico no Brasil. In: CORTEZ, L. A. B. (Coord.). Bioetanol de cana-de-açúcar: P\&D para produtividade e sustentabilidade. São Paulo: Blucher/Flapesp, 2010.

CHAMPAGNE, P. Feasibility of producing bio-ethanol from waste residues: A Canadian perspective: Feasibility of producing bio-ethanol from waste residues in Canada. Resour Conserv Recy 50, 211-230. 2007.

EVARISTO, J. J. Avaliação de diferentes reagentes na extração da pectina do albedo da laranja. Trabalho de Conclusão de Curso - TCC (Bacharelado em Química) - Centro de Ciências Exatas e Naturais do Departamento de Química. Universidade Regional de Blumenau, 2009.

FERREIRA, L. C. C. CARACTERIZAÇÃO DO POTENCIAL ENERGÉTICO ENTRE A PRODUÇÃO DE ETANOL CELULÓSICO E A COGERAÇÃO APARTIR DO BAGAÇO DE CANA. Projeto de Graduação (Graduação em Engenharia Mecânica). Faculdade de Tecnologia - Departamento de Engenharia Mecânica. Universidade de Brasília, 2012.

INTERNATIONAL ENERGY AGENCY. Sustainable Production of Second Generation Biofuels Potential and perspectives in major economies and developing countries. Paris, 2010 .

MONTIPÓ, S. Produção de ácido láctico a partir da casca de arroz. Dissertação de Mestrado, Universidade Federal de Santa Maria, Santa Maria-RS, 2012. 
SANTOS, M. S. R. Estudo de pré - tratamentos de palha e sabugo de milho visando a produção de etanol 2G. Dissertação de mestrado. Pós-graduação em Engenharia Química, Universdade Federal de Alagoas, Maceió-AL, 2014.

SILVA, O. G. Produção de etanol com utilização do bagaço da cana-de-açúcar. Trabalho de Conclusão de Curso (Graduação em Tecnologia de Biocombustíveis). Faculdade de Tecnologia de Araçatuba, SP, Fatec, 2010.

SILVA, V. F. N. Estudos de pré-tratamento e sacarificação enzimática de resíduos agroindustriais como etapas do processo de obtenção de etanol celulósico. Dissertação de mestrado. USP, Lorena-SP, 2009. 